2. Pedrizzetti G, Sengupta S, Caracciolo G, Park CS, Amaki M, Goliasch G, et al. Three-dimensional principal strain analysis for characterizing subclinical changes in left ventricular function. J Am Soc Echocardiog. 2014;27:1041-10450.e1.

3. Sato T, Calderon RJ, Klas B, Pedrizzetti G, Banerjee A. Simultaneous volumetric and functional assessment of the right ventricle in hypoplastic left heart syndrome after Fontan palliation, utilizing 3-dimensional speckle-tracking echocardiography. Circ J. 2020;84:235-44.
4. Mangual JO, Luca AD, Toncelli L, Domenichini F, Galanti G, Pedrizzetti G Three-dimensional reconstruction of the functional strain-line pattern in the left ventricle from 3-dimensional echocardiography. Circ Cardiovasc Imaging. 2012;5:808-9.

5. Haugaa KH, Grenne BL, Eek CH, Ersøll M, Valeur N, Svendsen JH, et al. Strain echocardiography improves risk prediction of ventricular arrhythmias after myocardial infarction. JACC Cardiovasc Imaging. 2013;6:841-50.
See Article page 1418.

\section{Commentary: Elucidating the mechanisms underlying left ventricular function recovery in patients with ischemic heart failure undergoing surgical remodeling: Physiology versus Empiricism}

Giuseppe Ambrosio, $\mathrm{MD}, \mathrm{PhD},{ }^{\mathrm{a}}$ Roberto Mattioli, MD, ${ }^{\mathrm{b}}$ and Erberto Carluccio, $\mathrm{MD}^{\mathrm{a}}$

Myocardial infarction (MI) is a major etiologic factor for heart failure (HF). In addition to muscle loss, MI alters left ventricular (LV) size and shape ("remodeling") through infarct expansion, scar formation, and hypertrophy of LV remote areas. ${ }^{1,2} \mathrm{LV}$ dilatation also increases wall stress, which further decreases pump efficiency and blunts the benefits of revascularization.

Surgical "reshaping" to revert postinfarction LV dilatation and remodeling has long been advocated. ${ }^{4}$ However, the ultimate benefits have been questioned, with surgeons wondering whether its aim is just achieving LV volume reduction, or restoring a more conical shape. ${ }^{5}$ Also, the

\footnotetext{
From ${ }^{\mathrm{a} C}$ Cardiology and Cardiovascular Pathophysiology, Santa Maria della Misericordia Hospital, University of Perugia, Perugia; and ${ }^{\mathrm{b}}$ IRCCS Multimedica, Milan, Italy.

Disclosures: The authors reported no conflicts of interest.

The Journal policy requires editors and reviewers to disclose conflicts of interest and to decline handling or reviewing manuscripts for which they may have a conflict of interest. The editors and reviewers of this article have no conflicts of interest.

Received for publication March 2, 2021; revisions received March 2, 2021; accepted for publication March 2, 2021; available ahead of print March 5, 2021.

Address for reprints: Giuseppe Ambrosio, MD, PhD, Cardiology and Cardiovascular Pathophysiology, Santa Maria della Misericordia Hospital, University of Perugia, Piazzale Menghini, 06132 Perugia, Italy (E-mail: giuseppe.ambrosio@ ospedale. perugia.it)

J Thorac Cardiovasc Surg 2023;165:1431-2

$0022-5223 / \$ 36.00$

Copyright (c) 2021 by The American Association for Thoracic Surgery

https://doi.org/10.1016/j.jtcvs.2021.03.006
}

Check for updates

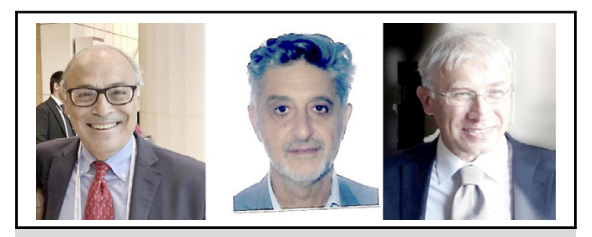

Giuseppe Ambrosio, MD, PhD, Roberto Mattioli, $\mathrm{MD}$, and Erberto Carluccio, MD

\section{CENTRAL MESSAGE \\ Why just reshaping! The impor- tance of remote myocardium in enhancing $L V$ function after ventricular surgical reconstruc- tion is highlighted by 3D speckle tracking echocardiography.}

STICH (Surgical Treatment for Ischemic Heart Failure) trial failed to demonstrate a clear benefit of adding LV surgical reconstruction to coronary artery bypass grafting in patients after an anterior $\mathrm{MI}^{6}$; still, that trial raised one important issue: would the benefits of surgical reduction of LV volume be offset by impaired diastolic distensibility/increased LV stiffness?

Choosing the optimal parameters to gauge improvement in LV function postoperatively is crucial when investigating the benefits of LV reshaping. Empirically, this has been pursued through measurements of LV ejection fraction (EF). That approach might prove fallacious, as EF is influenced by LV load conditions and other factors; more importantly, in this specific setting EF can be misleading. In fact, even if stroke volume remained unchanged after surgery (ie, no improvement of function), nonetheless expressing it relative to diastolic LV volume (which decreases postsurgery) would artifactually translate into greater EF; that would be just a "math improvement," not a physiologically relevant benefit.

Speckle-tracking echocardiography (STE) can precisely measure myocardial strain deformation and quantify LV thickening, shortening, and rotation dynamics; furthermore, 
it is relatively angle-independent and only marginally affected by motion artifacts. Implementing STE to 3-dimensional (3D) echocardiography further refines analysis of global and segmental myocardial function.

In this issue of the Journal, Castelvecchio and colleagues ${ }^{7}$ provide an important contribution to elucidate the mechanisms underlying LV functional improvement after surgical reconstruction. By 3D STE echocardiography, they studied 20 patients with anterior LV remodeling and ischemic HF, compared with matched controls. ${ }^{7} \mathrm{LV}$ global longitudinal strain and mechanical dispersion, which were markedly impaired at baseline, significantly improved 6 months after surgical ventricular reconstruction, consistent with improved LV contractility and synchronicity.

Interestingly, the greatest improvement occurred in remote myocardium, lending support to the concept that postischemic remodeling also involves noninfarcted segments, possibly dyssynergic as a consequence of hibernation or increased wall stress. ${ }^{8,9}$ Indeed, hibernation per se may contribute to LV remodeling, which can revert upon revascularization, ${ }^{8,9}$ whereas remote myocardium alterations (eg, myocardial relaxation time by cardiac magnetic resonance) are associated with the development of HF post-MI. ${ }^{10}$ However, the role of hibernation in the findings of Castelvecchio and colleagues remains speculative, as the presence of viable myocardium was not systematically sought.

Currently, 3D STE evaluation requires advanced equipment and skilled operators, which are not found at most sites. Yet, surgical ventricular reconstruction may have a role in selected patients with ischemic HF, particularly if small end-systolic volume postoperatively can be anticipated. In this respect, identifying candidates with high likelihood of improving after surgery will require a tighter collaboration between surgeons and cardiologists and implementing multimodality imaging study of LV remodeling.

\section{References}

1. Rahimtoola S, Dilsizian V, Marwick T, Vanoverschelde J. Chronic ischemic left ventricular dysfunction: from pathophysiology to imaging and its integration into clinical practice. JACC Cardiovasc Imaging. 2008;1:536-55.

2. French BA, Kramer CM. Mechanisms of post-infarct left ventricular remodeling. Drug Discov Today Dis Mech. 2007;4:185-96.

3. Konstam MA, Kramer DG, Patel AR, Maron MS, Udelson JE. Left ventricular remodeling in heart failure current concepts in clinical significance and assessment. JACC Cardiovasc Imaging. 2011;4:98-108.

4. Castelvecchio S, Garatti A, Gagliardotto PV, Menicanti L. Surgical ventricular reconstruction for ischaemic heart failure: state of the art. Eur Heart J Suppl. 2016;18(suppl E):E8-14.

5. Di Mauro M, Iacò AL, Bencivenga S, Clemente D, Marcon S, Asif M, et al. Left ventricular surgical remodelling: is it a matter of shape or volume? Eur J Cardiothorac Surg. 2015;47:473-9.

6. Jones RH, Velazquez EJ, Michler RE, Sopko G, Oh JK, O'Connor CM, et al. Coronary bypass surgery with or without surgical ventricular reconstruction. $N$ Engl J Med. 2009;360:1705-17.

7. Castelvecchio S, Frigelli M, Sturla F, Milani V, Pappalardo OA, Citarella M, et al. Elucidating the mechanisms underlying left ventricular function recovery in ischemic heart failure patients undergoing surgical remodeling: a 3-dimensional ultrasound analysis. J Thorac Cardiovasc Surg. 2023;165:1418-29.e4.

8. Carluccio E, Biagioli P, Alunni G, Murrone A, Giombolini C, Ragni T, et al. Patients with hibernating myocardium show altered left ventricular volumes and shape, which revert after revascularization: evidence that dyssynergy might directly induce cardiac remodeling. J Am Coll Cardiol. 2006;47:969-77.

9. Carluccio E, Biagioli P, Alunni G, Murrone A, Leonelli V, Giombolini C, et al. Effect of revascularizing viable myocardium on left ventricular diastolic function in patients with ischemic cardiomyopathy. Eur Heart J. 2009;30:1501-9.

10. Carrick D, Haig C, Rauhalammi S, Mordi AN, McEntegart M, Petrie MC, et al. Pathophysiology of LV remodeling in survivors of STEMI: inflammation, remote myocardium, and prognosis. JACC Cardiovasc Imaging. 2015;8:779-89. 